Article

\title{
Batch Fermentation Options for High Titer Bioethanol Production from a SPORL Pretreated Douglas-Fir Forest Residue without Detoxification
}

\author{
Mingyan Yang ${ }^{1,2,3}$, Hairui $\mathrm{Ji}^{2,4}$ and J.Y. Zhu ${ }^{2, *}$ \\ 1 School Environment Science Engineering, Chang'an University, Xi'an 710064, China; \\ yangmingyan67@163.com \\ 2 USDA Forest Service, Forest Products Laboratory, Madison, WI 53726, USA; jzhu@fs.fed.us \\ 3 Key Laboratory of Subsurface Hydrology and Ecological Effects in Arid Region, Ministry of Education, \\ Chang'an University, Xi'an 710064, China \\ 4 College of Life Science and Technology, Beijing University of Chemical Technology, Beijing 100029, China \\ * Correspondence: jzhu@fs.fed.us; Tel.: +1-608-231-9520
}

Academic Editor: Ronnie G. Willaert

Received: 3 June 2016; Accepted: 1 August 2016; Published: 11 August 2016

\begin{abstract}
This study evaluated batch fermentation modes, namely, separate hydrolysis and fermentation (SHF), quasi-simultaneous saccharification and fermentation (Q-SSF), and simultaneous saccharification and fermentation (SSF), and fermentation conditions, i.e., enzyme and yeast loadings, nutrient supplementation and sterilization, on high titer bioethanol production from SPORL-pretreated Douglas-fir forest residue without detoxification. The results indicated that Q-SSF and SSF were obviously superior to SHF operation in terms of ethanol yield. Enzyme loading had a strong positive correlation with ethanol yield in the range studied. Nutrient supplementation and sterility were not necessary for ethanol production from SPORL-pretreated Douglas-fir. Yeast loading had no substantial influence on ethanol yield for typical SSF conditions. After $96 \mathrm{~h}$ fermentation at $38^{\circ} \mathrm{C}$ on shake flask at $150 \mathrm{rpm}$, terminal ethanol titer of $43.2 \mathrm{~g} / \mathrm{L}$, or $75.1 \%$ theoretical based on untreated feedstock glucan, mannan, and xylan content was achieved, when SSF was conducted at whole slurry solids loading of $15 \%$ with enzyme and yeast loading of $20 \mathrm{FPU} / \mathrm{g}$ glucan and $1.8 \mathrm{~g} / \mathrm{kg}$ (wet), respectively, without nutrition supplementation and sterilization. It is believed that with mechanical mixing, enzyme loading can be reduced without reducing ethanol yield with extended fermentation duration.
\end{abstract}

Keywords: forest residue; pretreatment; liquefaction; enzymatic hydrolysis/saccharification; fermentation; high titer bioethanol; detoxification

\section{Introduction}

Fermentation of sugars from lignocelluloses has been proposed as a viable pathway for the production of renewable biofuels to supplement petro-fuels for sustainable economic development [1]. Feedstock is a major cost factor in producing cellulosic biofuels. Using low cost and underutilized feedstock such as harvest forest residues can be a winning proposition [2]. Forest residue can be sustainably produced in large quantities in various regions of the world [3,4], however, requires extensive pretreatment to remove its strong recalcitrance to enzymatic sugar production [5]. Severe pretreatments were often applied to remove this recalcitrance but resulted in the production of fermentation inhibitors [6,7]. Pretreatment optimization and strategies can substantially reduce inhibitor formation to facilitate high solids saccharification and fermentation without detoxification [8-12]. Proper management of inhibitor and sugar profiles in fermentation can improve ethanol productivity as xylose fermentation using Saccharomyces cerevisiae is especially sensitive to 
inhibitor profile $[13,14]$. Some studies suggest that initial sugar concentration can affect ethanol productivity $[10,15]$. Therefore, it is worthwhile to study the potential batch fermentation options to maximize ethanol production.

The objective of the present study is therefore to evaluate several batch fermentation approaches under various conditions for ethanol production from a softwood forest residue. The forest residue was pretreated by Sulfite Pretreatment to Overcome the Recalcitrance of Lignocelluloses (SPORL) [16]. SPORL was chosen for its robust performance in bioconversion of softwood biomass to sugars and biofuel [11,17]. Few processes have demonstrated good performance in effective removal of the recalcitrance of softwood biomass [5,18]. A SPORL pretreated Douglas-fir forest residue whole slurry from a previous study [10] at high $\mathrm{SO}_{2}$ loading was used because of its low inhibitors, relatively short pretreatment residence time of $1 \mathrm{~h}$, and potentially low metallurgy requirement due to the low pretreatment temperature of $140{ }^{\circ} \mathrm{C}$. Separated enzymatic hydrolysis and fermentation (SHF), simultaneous enzymatic saccharification and fermentation (SSF), as well as quasi-simultaneous enzymatic saccharification and fermentation (Q-SSF) were evaluated. In Q-SSF, the pretreated whole slurry solids (WSS) was first liquefied through a pre-hydrolysis period at elevated temperature optimized for the cellulase used, i.e., $50{ }^{\circ} \mathrm{C}$ for the present study. Fermentation was then performed after cooling down the liquefied WSS to the desired temperature for the yeast, i.e., $38^{\circ} \mathrm{C}$ in the present study. Ranges of liquefaction time, cellulase and yeast loadings were all evaluated in this study.

\section{Materials and Methods}

\subsection{Materials}

Douglas-fir forest residue was collected from a regeneration harvest in a primarily Douglas-fir stand in Lane County, OR, USA. The forest residue was ground and screened as described previously $[9,19]$ to reduce bark and ash content and dead load in transportation. The accept forest residues were labelled as FS-10 and shipped to USDA Forest Products Laboratory, Madison, WI, after air drying to a moisture content of approximately $15 \%$.

A commercial complex cellulase enzyme, Cellic ${ }^{\circledR}$ CTec3 (abbreviated CTec3), was complimentary provided by Novozymes North America (Franklinton, North Carolina, USA). The cellulase activity was $217 \mathrm{FPU} / \mathrm{mL}$ as calibrated by a literature method [20]. All the chemicals used were ACS reagent grade and purchased from Sigma-Aldrich (St. Louis, MO, USA).

Saccharomyces cerevisiae YRH400, an engineered fungal strain for xylose fermentation, was obtained from USDA Agriculture Research Service [21]. The strain was grown at $30{ }^{\circ} \mathrm{C}$ for 2 days on YPD agar plates containing $10 \mathrm{~g} / \mathrm{L}$ yeast extract, $20 \mathrm{~g} / \mathrm{L}$ peptone, $20 \mathrm{~g} / \mathrm{L}$ glucose, and $20 \mathrm{~g} / \mathrm{L}$ agar. A colony from the plate was transferred by loop to $50 \mathrm{~mL}$ liquid YPD medium in a $125 \mathrm{~mL}$ flask and cultured for overnight at $30^{\circ} \mathrm{C}$ with agitation at $150 \mathrm{rpm}$ on a shaking bed incubator (Thermo Fisher Scientific, model 4450, Waltham, MA, USA). The biomass concentration was monitored using optical density at $600 \mathrm{~nm}\left(\mathrm{OD}_{600}\right)$ by a UV-vis spectrophotometer (Model 8453, Agilent Technologies, Palo Alto, CA, USA). The yeast seed at logarithmic phase with an average $\mathrm{OD}_{600}$ of approximately 18 was harvested and centrifuged at $5000 \mathrm{rpm}$, wet solid pellet was collected for fermentation.

\subsection{Pretreatment}

SPORL pretreatment of Douglas fir in a pilot scale wood pulping digester of 390-L was described previously [10]. The same pretreated FS-10 whole slurry sample labeled as C-t60 was used in this study. The C-t60 was produced by pretreating FS-10 at $140{ }^{\circ} \mathrm{C}$ with a liquor to wood ratio (L/W) of $4: 1$ (L/kg) and a targeted total $\mathrm{SO}_{2}$ concentration of $80 \mathrm{~g} / \mathrm{L}$ and a combined (with magnesium oxide) $\mathrm{SO}_{2}$ loading of $11 \mathrm{~g} / \mathrm{L}$ in the pretreatment liquor. These chemical loadings were chosen to simulate the chemistry in a commercial sulfite pulp mill in the US that recovers magnesium in operation. The pretreatment lasted $60 \mathrm{~min}$ after $32 \mathrm{~min}$ of ramping to $140{ }^{\circ} \mathrm{C}$. Liquor circulation provided good mixing in reaction. 
The collected solids and neutralized liquor were disk milled together. The measured whole slurries had a total solids content of $21.6 \%$.

\subsection{Enzymatic Hydrolysis}

Enzymatic hydrolysis of the whole slurry solid (WSS) was carried out in $250 \mathrm{~mL}$ Erlenmeyer on a shaking incubator (Thermo Fisher Scientific, Model 4450, Waltham, MA, USA) to evaluate the effect of cellulase loading on WSS saccharification efficiency. Solid calcium carbonate was used to adjust the $\mathrm{pH}$ of the whole slurry of total solids of $15 \%(w / w)$ to approximately 5.5 . Elevated $\mathrm{pH}$ of 5.5 was used to reduce nonproductive cellulase binding to lignin [22,23]. Hydrolysis was conducted at $50{ }^{\circ} \mathrm{C}$ and incubator shaking frequency of $200 \mathrm{rpm}$ for $72 \mathrm{~h}$. CTec 3 loadings were 5, 10, $20 \mathrm{FPU} / \mathrm{g}$ glucan based on glucan in water insoluble solids (WIS). Hydrolysates were sampled periodically. At the end of enzymatic hydrolysis, solid residues were separated by centrifugation at $13,000 \times g$ for $5 \mathrm{~min}$. Hydrolysates were analyzed for glucose. Duplicate hydrolysis runs were performed. Means and standard deviations were used as error bars in plots.

\subsection{Enzymatic Saccharification and Fermentation}

Enzymatic saccharification and fermentation experiments of the SPORL whole slurry C-t60 were also carried out in $125 \mathrm{~mL}$ Erlenmeyer flasks on the same shaker incubator described in the previous section. The $\mathrm{pH}$ of the slurry was again adjusted to 5.5 using solid calcium carbonate. The enzymatic hydrolysis was conducted at $15 \%$ total solids loading $(w / w)$ and with CTec3 loading of $20 \mathrm{FPU} / \mathrm{g}$ of glucan. Hydrolysis was carried out at $50{ }^{\circ} \mathrm{C}$ and $200 \mathrm{rpm}$ for $72 \mathrm{~h}, 8 \mathrm{~h}$, and $0 \mathrm{~h}$, respectively, before subsequent separate saccharification and fermentation (SHF), quasi-simultaneous saccharification and fermentation (Q-SSF), and true simultaneous saccharification and fermentation (SSF). No sterilization was applied prior to all these fermentation runs. The cultured yeast broth with $\mathrm{OD}_{600}=18$ was directly applied to inoculate the enzyme loaded pretreated whole slurry at volumetric loadings of 6,8 , and $10 \%$, corresponding to wet yeast pellet (obtained by centrifuging at $5000 \mathrm{rpm}$ for $20 \mathrm{~min}$ ) of 1.3 , 1.8 , and $2.2 \mathrm{~g} / \mathrm{kg}$, respectively. The hydrolyzed or liquefied whole slurries were cooled down to $30^{\circ} \mathrm{C}$ for SHF and $38^{\circ} \mathrm{C}$ for Q-SSF and SSF.

Different enzyme loadings of 5, 10 and $20 \mathrm{FPU} / \mathrm{g}$ of glucan in WIS were used to evaluate the effect of enzyme dosage on ethanol production in SSF without pre-hydrolysis for liquefaction of solids.

Control fermentation runs were conducted in SSF mode at CTec3 loading of $20 \mathrm{FPU} / \mathrm{g}$ and yeast volumetric loading of $8 \%$ without sterilization but with the supplementation of nutrients: Yeast extract $=5 \mathrm{~g} / \mathrm{L},(\mathrm{NH} 4)_{2} \mathrm{SO}_{4}=2 \mathrm{~g} / \mathrm{L}, \mathrm{NaH}_{2} \mathrm{PO}_{4} 5=\mathrm{g} / \mathrm{L}$. The effect of without nutrient supplementation and the effect of sterilization were also studied. The whole slurry C-t60 was autoclaved at $121^{\circ} \mathrm{C}$ for $15 \mathrm{~min}$ prior to SSF fermentation for sterilization. The results were compared with the control run without sterilization.

All fermentation runs were carried out in duplicate. Samples were withdrawn at 4, 12, 24, 48, 72,96 , and $120 \mathrm{~h}$, and centrifuged at $13000 \times g$ for $5 \mathrm{~min}$. The supernatants were used for sugar and ethanol analyses. Furan concentrations were undetectable. Replicate analyses were conducted and the means and standard deviations of the duplicate fermentation runs were reported. Reported ethanol yield in percent theoretical was calculated based on the glucan, mannan, and xylan content in the untreated Douglas-fir residue FS-10 as expressed in the following equation:

$$
y_{\text {EtOH Theoretical }}(\%)=\frac{C_{E t O H} \times V_{\text {Broth }}}{0.511\left[\frac{C_{g l u}+C_{M a n}}{0.9}+\frac{C_{X y l}}{0.88}\right]} \times \frac{Y_{\text {Pretrta Total Solids }}}{m_{\text {Pretreated Total Solids }}} \times 100
$$

where $C_{E t O H}$ and $V_{B r o t h}$ are the terminal ethanol concentration $(\mathrm{g} / \mathrm{L})$ and the volume $(\mathrm{L})$ of the fermentation broth; $C_{G l u}, C_{M a n}, C_{X y l}$ are glucan, mannan, and xylan content $(\mathrm{g} / \mathrm{kg})$, respectively, in untreated woody biomass; $Y_{\text {Pretreated Total solids }}$ is the yield of total solids (in oven dry weight) from 
pretreating one $\mathrm{kg}$ of woody biomass $(\mathrm{g} / \mathrm{kg}) ; m_{\text {Pretrta Total Solids }}$ is the total solids in oven dry weight of the sample used in the fermentation experiment $(\mathrm{g})$.

\subsection{Analytical Methods}

Untreated and SPORL-pretreated FS-10 samples were first Wiley milled (Model No. 2; Arthur Thomas Co, Philadelphia, PA, USA) to 20 mesh and then hydrolyzed in two stages using sulfuric acid of $72 \%(v / v)$ at $30^{\circ} \mathrm{C}$ for $1 \mathrm{~h}$ and $3.6 \%(v / v)$ at $120^{\circ} \mathrm{C}$ for $1 \mathrm{~h}$, respectively, as described previously [24]. Carbohydrates of the acid hydrolysates were analyzed by high performance anion exchange chromatography with pulsed amperometric detection (Dionex ICS-5000, Thermo Scientific, Sunnyvale, CA, USA). Klason lignin was quantified gravimetrically.

The enzymatic hydrolysates and fermentation broths were analyzed for monosaccharides, ethanol, furans, and organic acids as described previously [10] using two Dionex HPLC systems (Ultimate 3000, Thermo Scientific, Sunnyvale, CA, USA) equipped with a RI (RI-101) and a UV (VWD-3400RS) detector, respectively. For fast analysis, glucose in the enzymatic hydrolysates was measured using a commercial glucose analyzer (YSI 2700S, YSI Inc., Yellow Springs, OH, USA).

\section{Results and Discussion}

\subsection{Compositional Analysis of SPORL Pretreated Douglas-Fir Residue}

The chemical composition of the untreated FS-10 is listed in Table 1 along with component recoveries from the SPORL pretreated washed water insoluble solids (WIS) and sugar and degradation products concentrations in the pretreatment spent liquor. Total of $186.88 \mathrm{~kg}$ spent liquor were collected which represent a loss of water of $13.12 \mathrm{~kg}$ ( $200 \mathrm{~kg}$ of total water was used including moisture in the pretreatment with liquor to wood ratio of $4: 1 \mathrm{~L} / \mathrm{kg}$ ) due to hot blow of the pretreated materials in the reactor at the end of pretreatment.

Table 1. Chemical composition of untreated and SPORL-pretreated unwashed wet solids and freely drainable spent liquor and total component recovery from the whole slurry solids.

\begin{tabular}{|c|c|c|c|c|}
\hline & Untreated FS-10 & $\begin{array}{c}\text { Pretreated FS-10 Wet } \\
\text { Solids }\end{array}$ & $\begin{array}{l}\text { Freely Drainable } \\
\text { Liquor }^{1}\end{array}$ & Total Recovery (\%) \\
\hline Wet weight (kg) & 66.41 & 126.50 & 94.35 & 88.1 \\
\hline Klason lignin $(\mathrm{kg})$ & 14.65 & 8.67 & 5.27 & 95.2 \\
\hline Arabinan $(\mathrm{kg})$ & 0.51 & 0.32 & & \\
\hline Galatan (kg) & 1.00 & 1.13 & & \\
\hline Xylan (kg) & 2.85 & 1.76 & $0.78(8.29)$ & 89.1 \\
\hline
\end{tabular}

\subsection{Evaluation of Pretreatment Effectiveness and Effect of Enzyme Loading on Saccharification}

Enzymatic hydrolysis of whole slurry solids (WSS) was conducted to evaluate the effectiveness of SPORL pretreatment for saccharification. Time-dependent substrate enzymatic digestibility (SED) shown in Figure 1 was defined as the percentage of glucan in WSS enzymatically hydrolyzed to glucose. Glucose release with $20 \mathrm{FPU} / \mathrm{g}$ glucan CTec3 loading increased sharply with time and reached over $90 \%$ within $24 \mathrm{~h}$ with a glucose titer of $65 \mathrm{~g} / \mathrm{L}$ and then increased slowly and reached $93 \%$ in $72 \mathrm{~h}$ with a titer of $67.7 \mathrm{~g} / \mathrm{L}$. The glucose release at the end of $72 \mathrm{~h}$ hydrolysis were 76.7 and $59.6 \%$ with a titer of 55.4 and $43.1 \mathrm{~g} / \mathrm{L}$ at $48 \mathrm{~h}$ at 10 and 5 FPU/g glucan loadings, respectively. These results suggested SPORL pretreatment was effective for maximal saccharification of Douglas-fir residue FS-10, in agreement with a previous study that evaluate the water insoluble solids (WIS) of the same pretreated FS-10 [10]. Even with a 4-fold reduction in cellulase loading 
from 20 to $5 \mathrm{FPU} / \mathrm{g}$ glucan, the enzymatic saccharification efficiency remained at approximately $60 \%$. Most of the fermentation experiments, nevertheless, were carried out using cellulase loading of $20 \mathrm{FPU} / \mathrm{g}$ glucan to facilitate liquefaction because mixing was done by shaking on a bed without mechanical mixing.

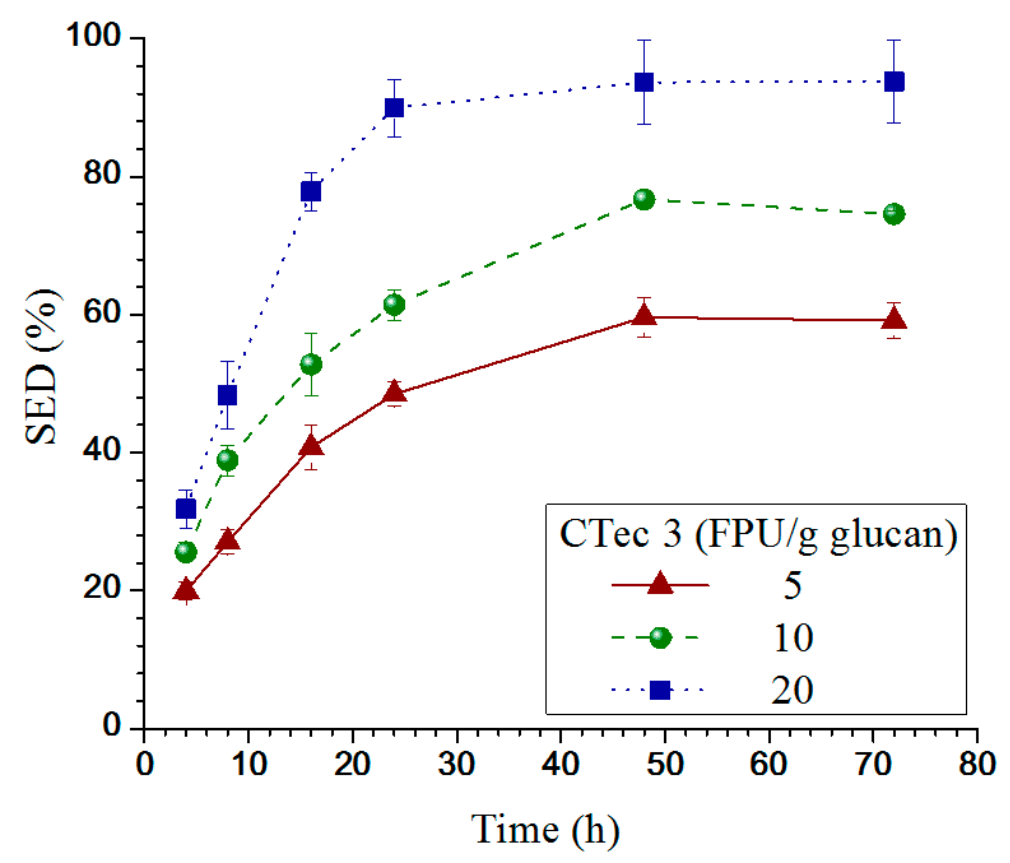

Figure 1. Time-dependent substrate enzymatic digestibility of SPORL-pretreated FS-10 WSS at 15\% total solids and three CTec3 loadings.

\subsection{Comprison of Three Different Fermentation Options on Ethanol Production}

Ethanol yield in a traditional SHF was low, probably due to end-product inhibition of the hydrolysis. Glucose inhibition becomes important when glucose concentration reaches over 50 g/L [25]. The concept of performing SSF was proposed in the 1970s [26] to eliminate end product inhibition. Furthermore, there are several additional potential advantages for using SSF, the combination of hydrolysis and fermentation decreases the number of vessels needed and, therefore investment costs. The decrease in capital investment has been estimated to be greater than $20 \%$. This is quite important since the capital costs can be expected to be comparable to the raw material costs in ethanol production from lignocelluloses [27]. In Q-SSF, lignocellulosic slurry was pre-hydrolyzed using enzymes to liquefy solids to produce a certain amount of monomeric and oligomeric sugars prior to fermentation using microorganisms. This approach avoids the disadvantage of low temperature hydrolysis required for yeast survival during liquefaction. The elevated liquefaction temperature, not only improved enzymatic activity, but also reduced the viscosity of the hydrolysate, which facilitates mixing for saccharification and fermentation.

Three fermentation strategies of SHF, Q-SSF and SSF of C-t60 WSS were carried at 15\% $(w / w)$ total solids loading with the supplementation of nutrient. The whole slurry was pre-hydrolyzed for $72 \mathrm{~h}, 8 \mathrm{~h}$, and $0 \mathrm{~h}$ at $50{ }^{\circ} \mathrm{C}$ and $200 \mathrm{rpm}$ on a shaking bed, which resulted in glucose concentrations of $67.8,32.1$ and $10 \mathrm{~g} / \mathrm{L}$, respectively. The yeast loading was $8 \% v / v$. The results showed both Q-SSF and SSF produced a higher terminal ethanol concentration than SHF (Figure 2a). An obvious lagging phase in ethanol production can be clearly observed in SHF in the first $12 \mathrm{~h}$, probably due to the high glucose concentration, which resulted in a terminal ethanol concentration of $38.6 \mathrm{~g} / \mathrm{L}$ at $96 \mathrm{~h}$. Compared with SHF, no visible lagging phase was observed in both Q-SFF and SFF, and ethanol production started immediately after inoculation though slower than SHF between 12 
and $24 \mathrm{~h}$, perhaps due to lower glucose concentration. In the first $36 \mathrm{~h}$, Q-SSF had higher ethanol productivity than SSF perhaps due to the availability of more glucose and the reduced viscosity in the Q-SSF slurry due to pre-hydrolysis and liquefaction. However, Q-SSF and SSF reached the same terminal ethanol concentration of $42.3 \mathrm{~g} / \mathrm{L}$ at $72 \mathrm{~h}$. Glucose concentration continued to increase for the SSF and Q-SSF runs even at the end of $96 \mathrm{~h}$, suggesting continued saccharification and better managing yeast activity or adding more yeast at this stage could further increase ethanol yield. Continued saccharification at the end of fermentation was also observed in a previous study [11].

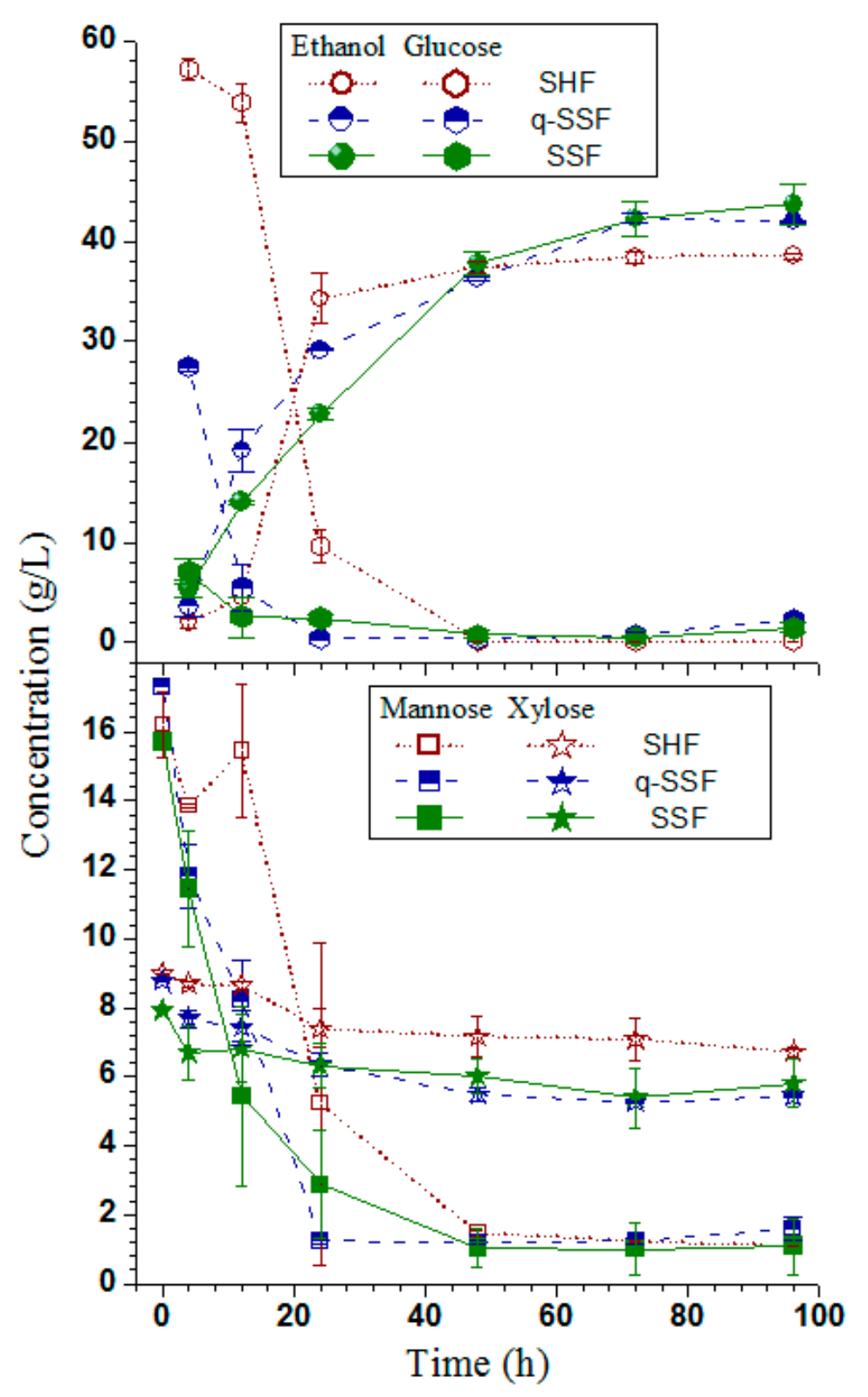

Figure 2. Comparisons of time-dependent fermentation results of SPORL pretreated Douglas-fir residue FS-10 among different fermentation options at CTec 3 of $20 \mathrm{FPU} / \mathrm{g}$ glucan and $8 \%(v / v)$ yeast loading. (a) Ethanol and glucose concentrations; (b) Mannose and xylose concentrations.

Time-dependent hemicellulosic sugar consumptions are shown in Figure 2b. Mannose was consumed rapidly by YRH400 in the first $48 \mathrm{~h}$, especially in the SSF and Q-SSF runs. This is probably because glucose concentration was lower in these two fermentations (Figure 2a) than that in the SHF run, which resulted in better utilization of mannose and even xylose to some extent. After $48 \mathrm{~h}$, 
glucose concentrations approaches zero and hemicellulosic sugar consumptions were pretty much completed in all three runs (Figure 2a,b). It appears that the yeast was starved and under stress, as discussed above, and incapable of consuming hemicellulosic sugars at very low concentrations. The final utilization of mannose in three fermentation runs, however, were very high, over $90 \%$. The final xylose consumption was $38 \%$ and $32 \%$ in q-SFF and SSF, respectively, higher than the $25 \%$ in SHF.

\subsection{Comprison of Different Enzyme Loadings in SSF Fermentation}

The results of enzymatic hydrolysis of WSS at different enzyme loadings indicated insufficient cellulose saccharification at 5 and 10 FPU/g glucan at 15\% loading of WSS (Figure 1). However, enzyme is a very important cost factor in bioethanol production [27]. SSF of WSS was carried out at enzyme loadings of 5, 10 and $20 \mathrm{FPU} / \mathrm{g}$ glucan to evaluate the effect of enzyme loading on ethanol production. The results shown in Figure 3a clearly indicated a strong positive correlation between enzyme loading and terminal ethanol yield. Ethanol concentration from 20 FPU/g glucan was much higher than 5 and $10 \mathrm{FPU} / \mathrm{g}$ glucan. It is interesting to notice that glucose concentration was highest at the highest enzyme loading of $20 \mathrm{FPU} / \mathrm{g}$ glucan during 4 to $24 \mathrm{~h}$, followed by loading of $10 \mathrm{FPU} / \mathrm{g}$ glucan, and lowest at $5 \mathrm{FPU} / \mathrm{g}$ glucan. This perhaps suggests rapid cellulose saccharification at high cellulase loadings and initial ( $0-12 \mathrm{~h}$ ) fermentation may be slower (Figure 2a). Glucose concentration was increased after $96 \mathrm{~h}$ at enzyme loadings of $10 \mathrm{FPU} / \mathrm{g}$ glucan (Figure 3a) similar to that observed in Figure 2a at $20 \mathrm{FPU} / \mathrm{g}$ glucan and in a previous study [11]. This observation indicates that better managing yeast activity can improve ethanol yield. Furthermore, ethanol concentration was not plateaued at the two low CTec 3 loadings of 5 and $10 \mathrm{FPU} / g$ glucan (Figure 3a), suggesting extending fermentation time can improve ethanol yield even at low cellulase loadings. One can balance capital and enzyme costs by using low cellulase loadings with extended fermentation time.

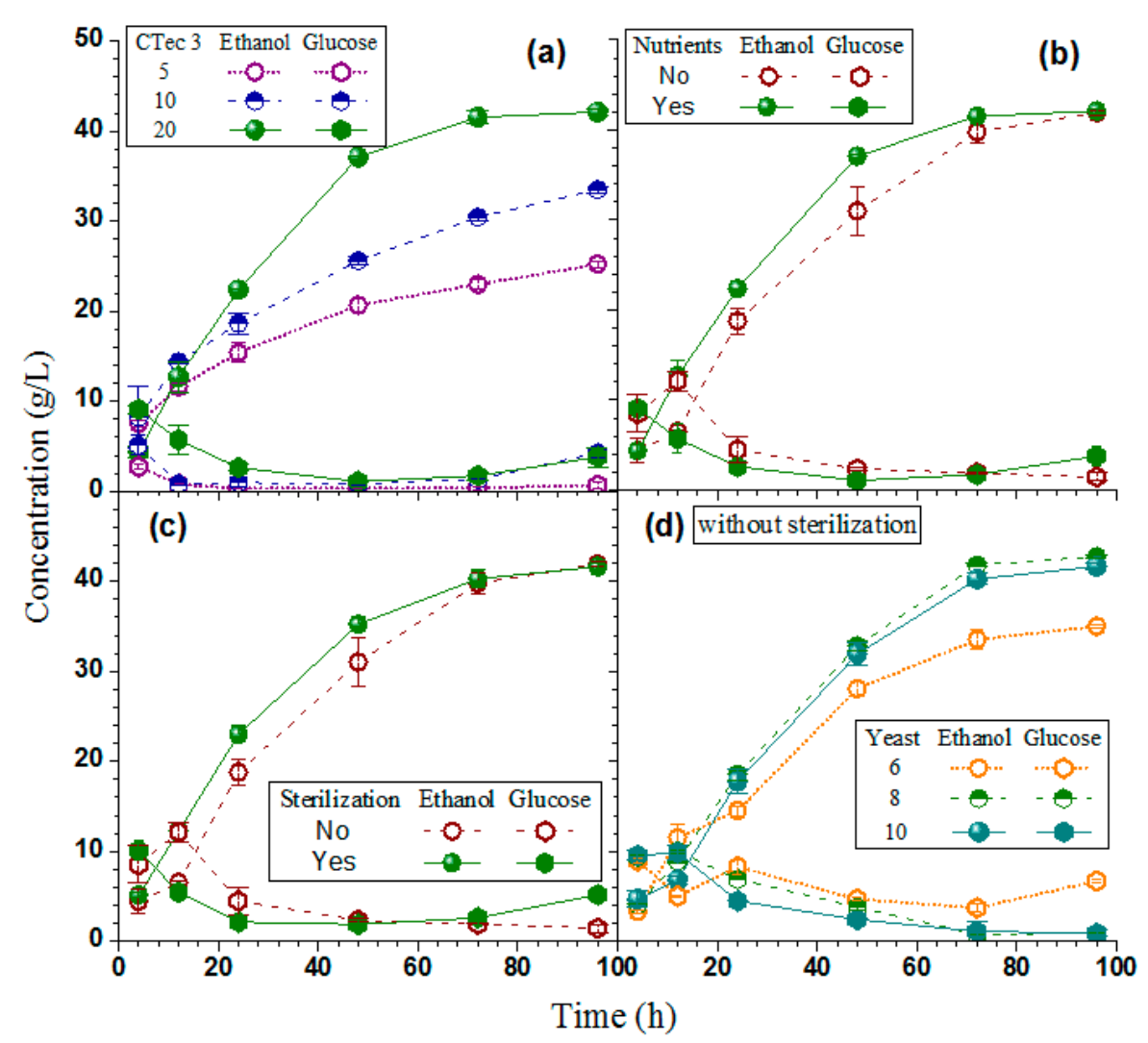

Figure 3. Effects of (a) cellulase loading; (b) nutrient supplementation; (c) sterilization, and (d) yeast loadings on time-dependent fermentation results of SPORL pretreated Douglas fir residue FS-10 WSS. 


\subsection{Effect of Nutrient Supplementation on the Ethanol Production}

Fermentation runs using SSF were carried out with and without the supplementation of nutrients at CTec3 loading of $20 \mathrm{FPU} / g$ glucan without sterilization. Ethanol production with nutrients supplementation was higher than that without before $96 \mathrm{~h}$ (Figure 3b), probably because the yeast needed more time to acclimatize in the media without nutrients. Terminal ethanol production at $96 \mathrm{~h}$, however, was the same $(43 \mathrm{~g} / \mathrm{L})$ with and without nutrients.

\subsection{Effect of Sterilization}

In general, the SPORL pretreated whole slurry C-t60 was quite sterile. However the pretreated FS-10 sample has been stored in a cold room for quite a few months. It is worth studying whether or not sterilization help ethanol productivity. The SSF results clearly showed a lagging phase within the first $12 \mathrm{~h}$ for the fermentation run without sterilization (Figure 3c). Glucose consumption was much faster when the sample was autoclaved at $121^{\circ} \mathrm{C}$ for $15 \mathrm{~min}$. This perhaps due to the fact that growth of Saccharomyces cerevisiae YRH400 was suppressed by other microorganisms that existed in the sample. After $48 \mathrm{~h}$, these microorganisms may not be able to survive due to elevated ethanol concentrations. The inoculated strain YRH400 became the dominant strain. As a result, terminal ethanol concentration at $96 \mathrm{~h}$ was not affected due to the lack of sterilization.

\subsection{Effect of Yeast Loading on the Ethanol Production}

In industrial practice, enzyme and yeast cell concentrations should be appropriately balanced to minimize the costs for yeast and enzyme production. A higher yeast concentration in the SSF can result in a lower overall ethanol yield when the cost for yeast production is taken into account [28]. However, lowering the yeast concentration may low the volumetric productivity, and lead to a stuck fermentation. Three different yeast volumetric loadings of $6 \%, 8 \%$, and $10 \%$ were inoculated in SSF with (not shown) and without (Figure 3d) sterilization. With sterilization, glucose consumption and the ethanol production were slightly slower at a lower yeast loading of $6 v / v \%$ in the first $24 \mathrm{~h}$, the ethanol production, however, reached the same concentration of approximately $43 \mathrm{~g} / \mathrm{L}$ at the two higher yeast loadings after $96 \mathrm{~h}$ fermentation. These results are in agreement with a study from the literature using $\mathrm{SO}_{2}$ steam explosion pretreated spruce [28]. When sterilization was not applied, however, glucose consumption and ethanol production were obviously slower at the lowest volumetric yeast loading of $6 \%$ than the two higher loadings of $8 \%$ and $10 \%$. The final ethanol concentration at $96 \mathrm{~h}$ was $35 \mathrm{~g} / \mathrm{L}$ at the lower yeast loading of $6 \%$, substantially lower than the approximately $42 \mathrm{~g} / \mathrm{L}$ at the two higher yeast loadings. This suggests sterilization can suppress other microorganism growth, which allows low yeast loading in ethanol fermentation.

\section{Conclusions}

The whole slurry solids (WSS) obtained from SPORL-pretreated Douglas-fir was evaluated for the production of bioethanol using Saccharomyces cerevisiae YRH400. The production of ethanol was investigated in a batch fermentation using modes, i.e., separate hydrolysis and fermentation (SHF), Quasi-simultaneous saccharification and fermentation (Q-SSF), and simultaneous saccharification and fermentation (SSF). Under SSF, the effects of different enzyme and yeast loadings, nutrient supplementation, and sterilization of the substrate on ethanol production were investigated. A final ethanol titer of $43.2 \mathrm{~g} / \mathrm{L}$ was achieved when SSF was conducted at whole slurry solids loading of $15 \%$, enzyme and yeast loading of $20 \mathrm{FPU} / \mathrm{g}$ glucan and $1.8 \mathrm{~g} / \mathrm{kg}$ yeast loading (wet cell), respectively, with sterilization but without nutrition supplementation.

Acknowledgments: The authors would like to acknowledge the financial support of the Agriculture and Food Research Initiative (AFRI) Competitive grant (No. 2011-68005-30416), USDA National Institute of Food and Agriculture (NIFA) through the Northwest Advanced Renewables Alliance (NARA). The authors also appreciate Novozymes North America for providing the CTec3 enzymes; Fred Matt of USFS-FPL for conducting the chemical composition analysis of forest residue samples; Bruce Dien and Ron Hector of USDA-ARS for providing the 
YRH-400 strain. Rolland Gleisner (USDA Forest Products Lab (FPL)) and William Gilles (Formerly with FPL) conducted pilot scale SPORL pretreatment. Funding was also received from The Chinese Scholarship Council for the visiting appointment of Mingyan Yang at the USDA Forest Products Lab.

Author Contributions: Mingyan Yang and J.Y. Zhu conceived and designed the experiments; Mingyan Yang conducted the experiments; Hairui Ji conducted analytical work and calculations. Mingyan Yang and J.Y. Zhu analyzed the results and wrote the paper.

Conflicts of Interest: J.Y. Zhu is a co-inventor of the SPORL technology. The founding sponsors had no role in the design of the study; in the collection, analyses, or interpretation of data; in the writing of the manuscript, and in the decision to publish the results.

\section{References}

1. U.S. DOE. Breaking the Biological Barriers to Cellulosic Ethanol: A Joint Research Agenda. A Research Road Map Resulting from the Biomass to Biofuel Workshop Sponsored by The Department of Energy; U.S. Department of Energy: Rockville, MD, USA, 2005.

2. National Research Council. Renewable Fuel Standard: Potential Economic and Environmental Effects of US Biofuel Policy; The Natinal Academies Press: Washington, WA, USA, 2011.

3. Gan, J.; Smith, C.T. Availability of logging residues and potential for electricity production and carbon displacement in the USA. Biomass Bioenerg. 2006, 30, 1011-1020. [CrossRef]

4. $\quad$ Perlack, R.D.; Stokes, B.J.; DOE. 2011. U.S. Billion-Ton Update: Biomass Supply for a Bioenergy and Bioproducts Industry; Oakridge National Laboratory: Oak Ridge, TN, USA, 2011.

5. Zhu, J.Y.; Pan, X.J. Woody Biomass Pretreatment for Cellulosic Ethanol Production: Technology and Energy Consumption Evaluation. Bioresour. Technol. 2010, 101, 4992-5002. [CrossRef] [PubMed]

6. Larsson, S.; Palmqvist, E.; Hahn-Hagerdal, B.; Tengborg, C.; Stenberg, K.; Zacchi, G.; Nilvebrant, N.-O. The generation of fermentation inhibitors during dilute acid hydrolysis of softwood. Enzyme Microb. Technol. 1999, 24, 151-159. [CrossRef]

7. Zhou, H.; Leu, S.-Y.; Wu, X.; Zhu, J.Y.; Gleisner, R.; Yang, D.; Qiu, X.; Horn, E. Comparisons of high titer ethanol production and lignosulfonate properties by SPORL pretreatment of lodgepole pine at two temperatures. RSC Adv. 2014, 4, 27033-27038. [CrossRef]

8. Zhang, C.; Houtman, C.J.; Zhu, J.Y. Using low temperature to balance enzymatic saccharification and furan formation in SPORL pretreatment of Douglas-fir. Process Biochem. 2014, 49, 466-473. [CrossRef]

9. Cheng, J.; Leu, S.-Y.; Zhu, J.Y.; Gleisner, R. High titer and yield ethanol production from undetoxified whole slurry of Douglas-fir forest residue using pH-profiling in SPORL. Biotechnol. Biofuels 2015, 8, 22. [CrossRef] [PubMed]

10. Gu, F.; Gilles, W.; Gleisner, R.; Zhu, J.Y. Fermentative high titer ethanol production from a Douglas-fir forest residue without detoxification using SPORL: High $\mathrm{SO}_{2}$ loading at a low temperature. Ind. Biotechnol. 2016, 12, 168-175. [CrossRef]

11. Zhu, J.Y.; Chandra, M.S.; Gu, F.; Gleisner, R.; Reiner, R.; Sessions, J.; Marrs, G.; Gao, J.; Anderson, D. Using sulfite chemistry for robust bioconversion of Douglas-fir forest residue to bioethanol at high titer and lignosulfonate: A pilot-scale evaluation. Bioresour. Technol. 2015, 179, 390-397. [CrossRef] [PubMed]

12. Zhou, H.; Zhu, J.Y.; Gleisner, R.; Qiu, X.; Horn, E.; Negron, J. Pilot-scale demonstration of SPORL for bioconversion of lodgepole pine to bio-ethanol and lignosulfonate. Holzforschung 2016, 70, 21-30.

13. Zhou, H.; Lan, T.; Dien, B.S.; Hector, R.E.; Zhu, J.Y. Comparisons of Five Saccharomyces cerevisiae strains for Ethanol Production from SPORL Pretreated Lodgepole Pine. Biotechnol. Prog. 2014, 30, 1076-1083. [CrossRef] [PubMed]

14. Almeida, J.R.M.; Runquist, D.; Sànchez Nogué, V.; Lidén, G.; Gorwa-Grauslund, M.F. Stress-related challenges in pentose fermentation to ethanol by the yeast Saccharomyces cerevisiae. Biotechnol. J. 2011, 6, 286-299. [CrossRef] [PubMed]

15. Hoyer, K.; Galbe, M.; Zacchi, G. The effect of prehydrolysis and improved mixing on high-solids batch simultaneous saccharification and fermentation of spruce to ethanol. Process Biochem. 2013, 48, $289-293$. [CrossRef]

16. Zhu, J.Y.; Pan, X.J.; Wang, G.S.; Gleisner, R. Sulfite pretreatment (SPORL) for robust enzymatic saccharification of spruce and red pine. Bioresour. Technol. 2009, 100, 2411-2418. [CrossRef] [PubMed] 
17. Leu, S.-Y.; Gleisner, R.; Zhu, J.Y.; Sessions, J.; Marrs, G. Robust Enzymatic Saccharification of a Douglas-fir Forest Harvest Residue by SPORL. Biomass Bioenerg. 2013, 59, 393-401. [CrossRef]

18. Yamamoto, M.; Niskanen, T.; Iakovlev, M.; Ojamo, H.; van Heiningen, A. The effect of bark on sulfur dioxide-ethanol-water fractionation and enzymatic hydrolysis of forest biomass. Bioresour. Technol. 2014, 167, 390-397. [CrossRef] [PubMed]

19. Zhang, C.; Zhu, J.Y.; Gleisner, R.; Sessions, J. Fractionation of Forest Residues of Douglas-fir for Fermentable Sugar Production by SPORL Pretreatment. Bioenerg. Res. 2012, 5, 978-988. [CrossRef]

20. Wood, T.M.; Bhat, M. Methods for Measuring Cellulase Activities. In Methods in Enzymology; Colowick, S.P., Kaplan, N.O., Eds.; Academic Press, Inc.: New York, NY, USA, 1988; pp. 87-112.

21. Hector, R.E.; Dien, B.S.; Cotta, M.A.; Qureshi, N. Engineering industrial Saccharomyces cerevisiae strains for xylose fermentation and comparison for switchgrass conversion. J. Ind. Microbio. Biotechnol. 2011, 38, 1193-1202. [CrossRef] [PubMed]

22. Lan, T.Q.; Lou, H.; Zhu, J.Y. Enzymatic saccharification of lignocelluloses should be conducted at elevated pH 5.2-6.2. Bioenerg. Res. 2013, 6, 476-485. [CrossRef]

23. Lou, H.; Zhu, J.Y.; Lan, T.Q.; Lai, H.; Qiu, X. pH-induced lignin surface modification to reduce nonspecific cellulase binding and enhance enzymatic saccharification of lignocelluloses. ChemSusChem 2013, 6, 919-927. [CrossRef] [PubMed]

24. Luo, X.; Gleisner, R.; Tian, S.; Negron, J.; Horn, E.; Pan, X.J.; Zhu, J.Y. Evaluation of mountain beetle infested lodgepole pine for cellulosic ethanol production by SPORL pretreatment. Ind. Eng. Chem. Res. 2010, 49, 8258-8266. [CrossRef]

25. Holtzapple, M.; Cognata, M.; Shu, Y.; Hendrickson, C. Inhibition of Trichoderma reesei cellulase by sugars and solvents. Biotechnol. Bioeng. 1990, 36, 275-287. [CrossRef] [PubMed]

26. Gauss, W.F.; Suzuki, S.; Takagi, M. Manufacture of Alcohol from Cellulosic Materials Using Plural Ferments. U.S. Patent 3990944 A, 9 November 1976.

27. Olofsson, K.; Bertilsson, M.; Lidén, G. A short review on SSF-An interesting process option for ethanol production from lignocellulosic feedstocks. Biotechnol. Biofuels 2008, 1, 7. [CrossRef] [PubMed]

28. Sassner, P.; Galbe, M.; Zacchi, G. Bioethanol production based on simultaneous saccharification and fermentation of steam-pretreated Salix at high dry-matter content. Enzyme Microb. Technol. 2006, 39, 756-762. [CrossRef]

(C) 2016 by the authors; licensee MDPI, Basel, Switzerland. This article is an open access article distributed under the terms and conditions of the Creative Commons Attribution (CC-BY) license (http:/ / creativecommons.org/licenses/by/4.0/). 